\title{
Morphing in Form Finding Stage through the Architectural Design Process
}

\author{
Sarah Ismail Hassan Soliman \\ Teaching Assistant. at Arch. Department \\ Faculty of Engineering-Mataria
}

Prof. Mohamed Alaa Mandour

Professor of Architecture- Arch. Department

Faculty of Engineering-Mataria
Dr. Hala Adeeb

Assistant Prof.-Arch Department

Faculty of Engineering-Mataria

\section{Introduction:}

Nature has been always a main source of inspiration for human being through different fields, in which, he has always built tools and techniques for development in various life fields inspired in many cases from nature; between these inspiring the rules and phenomena that governed nature, such as rules of form and formation in nature, which is known as metamorphosis. From the Stone Age till the digital era, each era has witnessed a various inspiration from nature to create new innovations throughout our history to retire the old ways and techniques of doing things and ultimately establishing new ways of life.

Today, and especially in the architectural field we can find that architecture has inspired a lot of its concepts from nature, as metamorphosis rules that depended on transformation processes, which appeared recently in architecture under the term of morphing, in which the research will concentrate on. These new rules and inspirations not only affected the expressionism and symbolism of the architecture form, but also it influences the architecture design process by many techniques that replace our traditional ways of designing and revolutionize how we conduct the future and how architects live in this digital world with a new methodologies and techniques in the architecture design specially in form finding process.

Firstly, the paper will describe the traditional design process and its stages additionally where and when the form stage comes during this stage. Secondly, it attempts to illustrate the techniques that have been added through the design process by the architectural pioneers through the twenty-one century, and how it affects the phases of design process specially the form finding stage. Ending by illustrating the process of morphing and how it can be implemented within the architectural design process, to enhance the qualities of architectural design, aiming to reach a new design process and reaching new form finding techniques that can facilitate the ability of designing new forms, which can express new architectural paradigm. 


\section{The Definition of Architectural Design:}

Designing cannot be considered as a linear process with a specify task leading to only one possible solution, designing is a reciprocal action and reflection (Burnard Lupen, 1997). So It is difficult to put a static definition to variable condition, but basically, we can find primary definitions to the architectural design term through the following:

A Concept that focuses on the components or elements of a structure or system and unifies them into a coherent and functional whole, according to a particular approach in achieving the objective(s) under the given constraints or limitations.

The creation of a plan or convention for the construction of an object, system or measurable human interaction (Cambridge Dictionary, 2018).

A roadmap or a strategic approach for someone to achieve a unique expectation. It defines the specifications, plans, parameters, activities, processes and how and what to do within legal, political, social, environmental, safety and economic constraints in achieving that objective (Don Kumaragamage, 2011).

Planning to manufacture an object, system, component or structure, Thus the word "design" can be used as a noun or a verb. In a broader sense, design is an applied art and engineering that integrates with technology. While the definition of design is fairly broad, design has a myriad of specifications that professionals utilize in their fields, (Bryan Lawson, 2005).

Whoever makes a design, whether it is a building, or a part of a town or a park, is basically concerned with a given program and a location or a site. Additionally, designers are faced with series of fixed precepts and unwritten demands informed by a particular culture or conventions. Subsequently, the designs must satisfy conditions of usefulness and constructions, these aspects don't arise in a fixed, logical order and knowing how to fulfill these requirements and expectations is one of the main problems facing the designers with each project. All relevant aspects need to be subjected to a critical scrutiny. So designers must interpret the task and adjust the relative importance of the various requirements and expectations, according to their considerations, conclusions and viewpoint. This act of interpreting is the preliminary step when embarking on a design, (Burnard Lupen, 1997).

Subsequently, Architectural design is a combination of graphical and theoretical problems, solving these problems are achieved through the design processes, methods and approaches, in which the designers' use thinking, sketches, drawing and modeling, and any other tools and techniques, to achieve the required creative results, (V. Goel, 1995). 


\section{Traditional Architectural Design Process:}

The Architectural design process is the scientific study of existing ideas, thought and thinking in getting detail solution of a design problem. It's explain that the difference between architectural design process and scientific methods is that, architectural design is concerned with how things ought to be done while natural sciences are concerned with how things are, (H. Simon-1969). Generally, it is considered that the difference between architectural, mechanical and industrial design processes is

$\square$ the aspect of the problem considered.

$\square$ the primary source of knowledge.

$\square$ the degree of commitment made to output statement.

$\square$ the level of details.

$\square$ the method of morphing and transformation.

The design process includes many phases starting from firstly the pre-design phase (assimilation), which comprise another sub stages: data and information, planning study, site analysis, and zoning study. Secondly, comes the schematic phase (design concept), which includes: alternative ideas, design sketches, establish design direction in terms of plan, section, elevation and form creating. And the phases end in some of the classifications with the third phase development phase, which comprise other stages as: development the schematic ideas, put the structure proposal and choosing the finishing materials. But in other classification the third phase (concept development) is not the final and includes: Develop design concept and review additional requirements. Finally ends with the

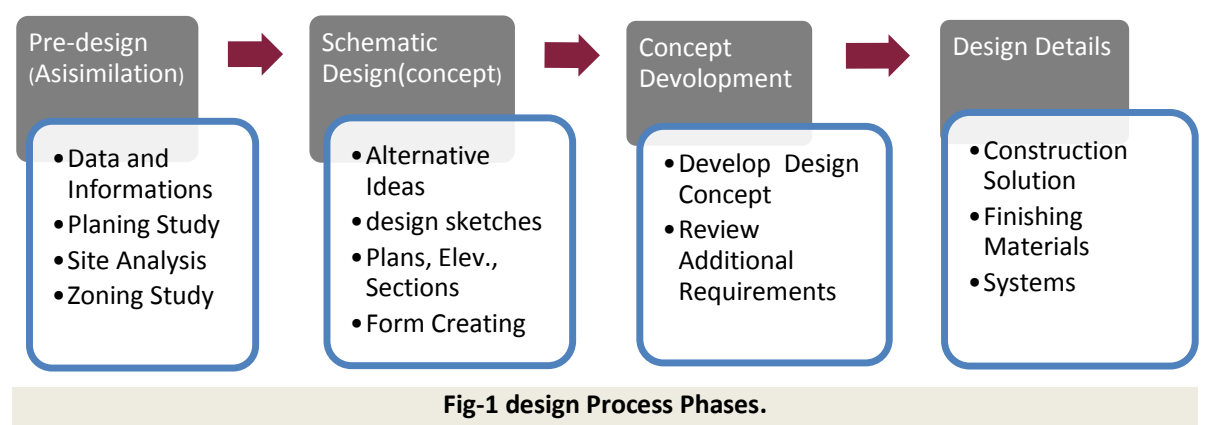

detailed design (improvement) whic $\mathrm{h}$ includes: construction solutions, finishing materials and systems as shown in the following diagram, (Bryan Lawson, 2005). 
In this sequence, as studied before, whereas the research is striving to study morphing methodologies in the architectural design process, the research will concentrate how the design process transforms and will concentrate on the form finding Stage, which is branched in the traditional design process from the schematic design phase and came in a later stage after the alternative ideas, design sketches, plans, elevations, and section.

\section{Morphing in the phase of Form Finding (Through Contemporary Architects' thoughts):}

The previous study shows the phases of the design process and illustrates the form stage that was branched under the schematic design phase, which depended on many traditional techniques, like putting alternative solutions, design sketches, and converting sketches into plans, elevations then finally creating forms. But with the design thinking transformations by the end of the twentieth-one century, many studies and applications have been made to develop the form finding stage, in an attempt to produce new architecture formations, which convey the philosophical and the technological transformations in the new era.

The traditional design techniques such as using regular and irregular forms, transformation of form whether additive or subtractive or dimensional manipulation, collision of geometry, rotated grid, and form articulation. Such techniques are used to generate traditional architectural forms that characterized by simplicity. However, the architecture of this era that featured by spatial complexity and ambiguity cannot be generated by this simple way; example of this architecture is embodied in Hadid and Thom Mayne works and many other contemporary architects. This complexity could not be achieved except with the assistance of new architectural programs which translate the imagination of architects to applicable projects.

In this sequence, and in the following part, the research will review and illustrate form finding new methodologies by using morphing techniques, through the works of firstly Gaudi who was as studied before one of the first architects that used morphing concepts in his design process, and then studding the works of the most important architectural pioneers of the new era, in which their designs dealt with morphing concepts by different ways, and this to reach the most important morphing techniques which can be used in form finding stage in the architectural design process. 


\subsection{Morphing Methodologies in Gaudi's Thoughts:}

It has been to Gaudi's attempts a great impact in developing and changing the modality, methods and techniques of the form design stage through the design process, where he realized and achieved new techniques, which depended on morphing processes, to produce new architectural formations that is not standard and traditional, as Gaudi effectively invented a kind of "parametric" design process long before the invention of the computer by using different techniques and tools. In this context Gaudi suggested many techniques in form finding:

\subsubsection{Physical Models:}

Gaudi hated drawing and preferred to use models as design tools to help him to morph during design process; especially ones made of chains hung from a ceiling, or strings with small weights fig-3 and plaster models too fig-2, (Santiago Huerta -2006).

\subsubsection{Catenary Methods:}

Gaudi used the catenary method for rendering the interior and exterior shapes of buildings by applying this tension-compression analogy to chains hanging from chains (or arches superimposed on arches) asymmetrically, permitting him to design more fluid architecture fig-4, (Dan Chak-2014).

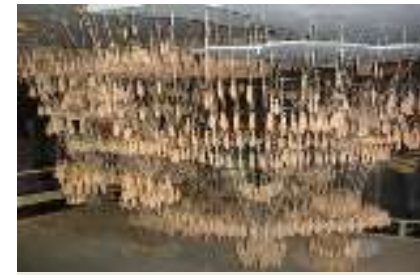

Fig-2 Funicular chain string model of Colonia Güell church project by Gaudi.

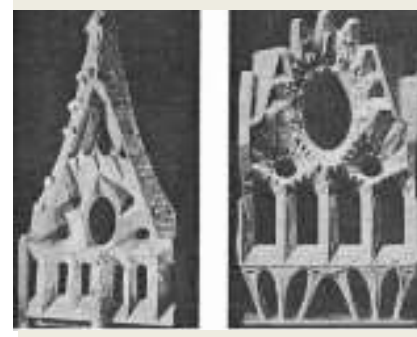

Fig-3 Plaster model of the grada Sagraah Familia walls window by Gaudi.

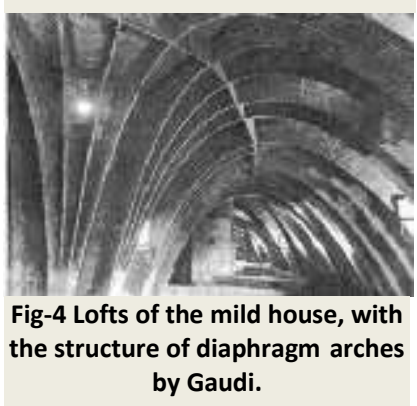

\subsubsection{Shapes Morphing (transformation):}

Gaudi used hyperboloids, parabolas, elicoids shapes and combining them for more complicated shaped fig-5, through physical models, he was able to make shapes transformations, (Jane R. Burry, Mark C. Burry-2006).
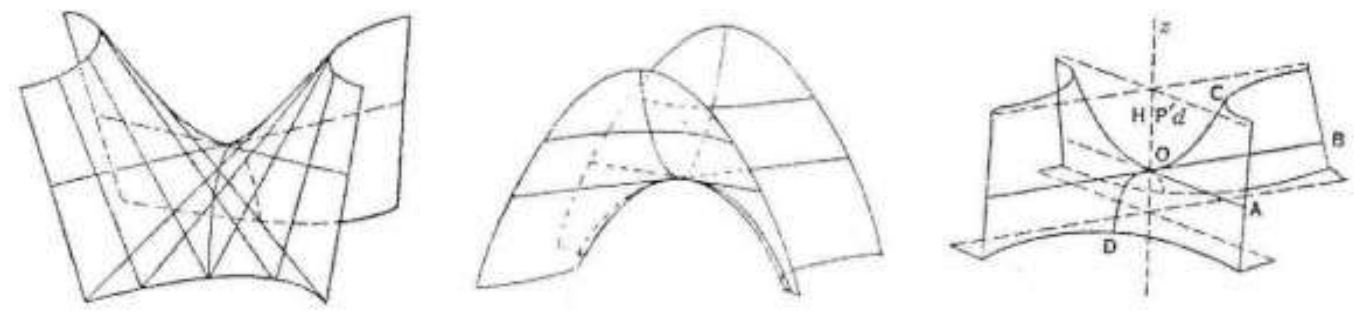

Fig-5 Hyperbolic-paraboloid surfaces. ${ }^{2}$ 


\subsubsection{Columns Morphing:}

The Column of Four:

One of Gaudi's novel solution for columns consisted in the use of two opposite rotations of the same shape, once clockwise and another counterclockwise as in fig-6, the first image shows the rotation of 22.5 of the rectangular shape. The second image shows the same shape with the rotation angle done in the opposite direction. The following image shows the superimposition of the two rotated shapes, which is only possible to visualize in a computer model. The last image shows the Boolean intersection of the two rotated shapes, generates the form of the column. This column is known as the Column of Four that is generated by a square shape, (Barrois Carlos2005).

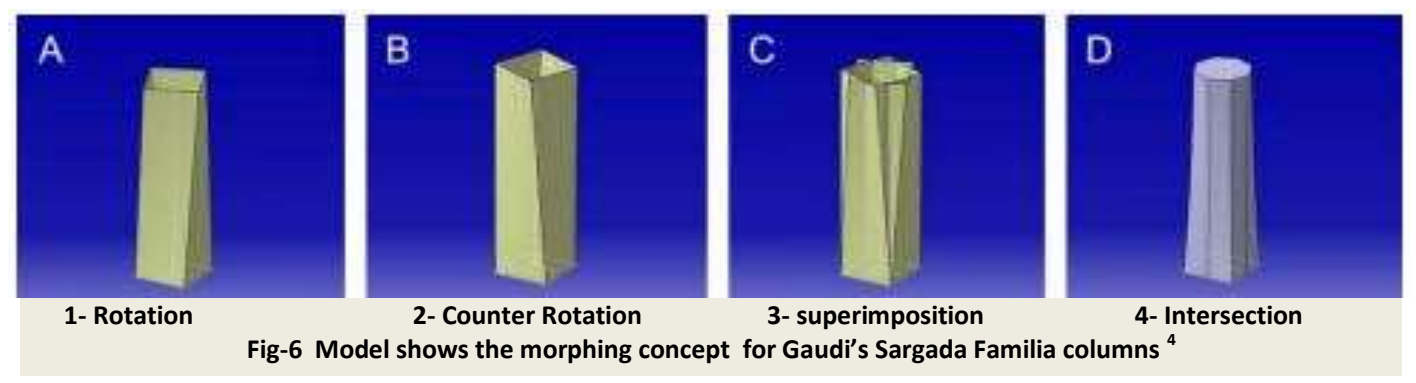

The Rectangular Knot Column:

the columns knot of the lateral nave of the Sagrada Familia, which was so complicated, the knot shapes according to the counter rotation procedure prescribed by Gaudi, through "Barrois Carlos" experiment which is illustrated through fig-7, it shows the sequence for the generation of the knot parametric model. The first stage was to create the top and bottom figures and locate them in parallel planes at a distance equivalent to the height of the column knot. A pair of top bottom figures was created for each rotation. This wireframe model is called the parametric skeleton (step 1). A surface fitting algorithm was applied to each pair of top-bottom shapes producing both the rotation and counter-rotation shapes (step 2-3). The two generated shapes were used to perform the Boolean intersection that generates the knot shape (step 4). Although this procedure of blending between two shapes was not described by Gaudi, nor any other researchers and scholars, the resulting columns were not only geometrically accurate, but also visually correct when compared to the original Gaudi models, (Barrois Carlos-2005).
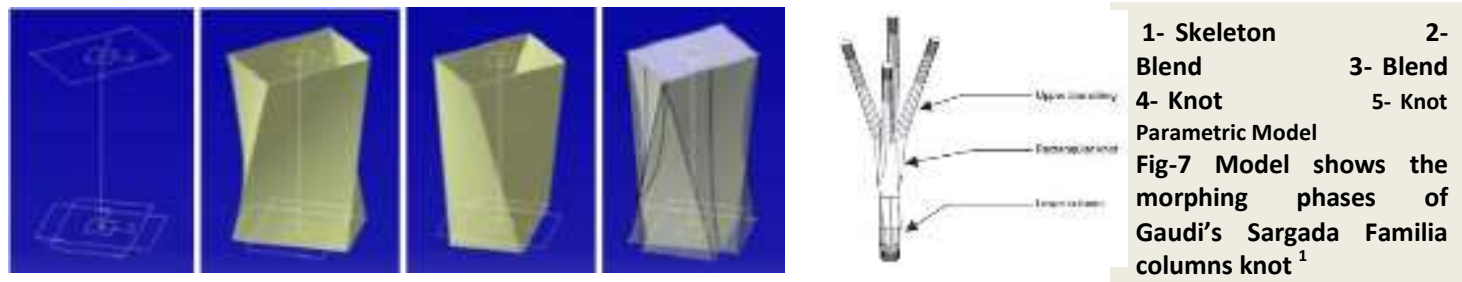

columns knot ${ }^{1}$ 


\subsection{Morphing Methodologies in Frank O Gehry's Thoughts:}

Frank Gehry is one of the most important architects that has different design strategies which lead to different architectural output. His earliest educational influences involved modernism, so one of the most common early design strategies that Frank Gehry applied in his projects was "the pile of boxes strategy", which emulates the modernism but in more dynamic way.

Also, Gehry sees architecture as an art. He manipulates the constraints of the project, then expresses his creation. For him, expression is essential in architecture; buildings cannot be faceless, like in modernism. Thus, he approaches each building as a sculptural object, each piece of architecture as a painting. He knows European art history and contemporary sculpture and painting, so his inspirations come from art and his role models are artists, his designs by pushing the limits of undecidability, like cubist artists. There is no ugly or pretty, no right or wrong in this process. Gehry's architecture has no real rules; it's open-ended and experiential architecture, like art.

Consequently, Gehry found that the key to success is complete creative freedom in a project. he works to create buildings with movement and feeling, which expresses the morphing concept in his designs. He has created a unique form of architecture, commonly referred to as liquid architecture, he uses movement and morphing as a part of his language, as he believes that movement is pervasive in our time and culture, like chaos. Gehry relates to the fast society, the fast world we live in; thus, he expresses emotion through a sense of movement and transformation, (Ela Poursani-2018)

Gehry begins the design process with the building program, which is a list of the functional requirements of a building, then he works in $3 d$ sketches and converting it to extensive physical modelling at multiple scales, in which both the functional and formal aspects of a project are explored in detail. Rather than designing on a two-dimensional plane and extruding the model as a finished project, modelling at various scales throughout the design process keeps the architects focused on the building, so that the model is not an end in itself, but a representation and a start. After that he transforms his concepts to a "smart" digital design, by using software to optimize designs and translate them directly into a process of fabrication and construction as shown in fig-8.

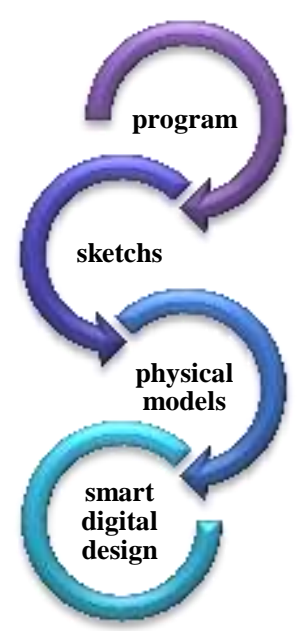

Fig-8 The operational cycle for Gehry strategy of design - by the researcher

Jim Glymph, Gehry's "office hippie," turned to a software called CATIA, (a C++ software package developed by an aerospace manufacturer). "CATIA" described digital models using parametric Bézier curves (or vectors) and 3D surface algorithms. The model is defined by a set of control points and the mathematical functions, or surfaces, that stretch between them. The parameters of 
these functions can be freely adjusted, making a Bézier surface accurate at any scale, (Lian Chang-2015).

\section{- Frank O Gehry's Techniques in Form Finding:}

Gehry's techniques in designing Form stage depended on 3d sketches, physical modeling and smart digital design to reach different architecture language that reflected in many of them the Morphing concepts. His design language appeared in many unconventional techniques, which he applied through his projects. Most of Ghery's techniques are about the concepts of decomposition, fusion, tension, and continuity. Table- 1 shows the most important techniques that Ghery used in his form designing stage and how it has been applied in his projects, (Lauren Bergman-2015).

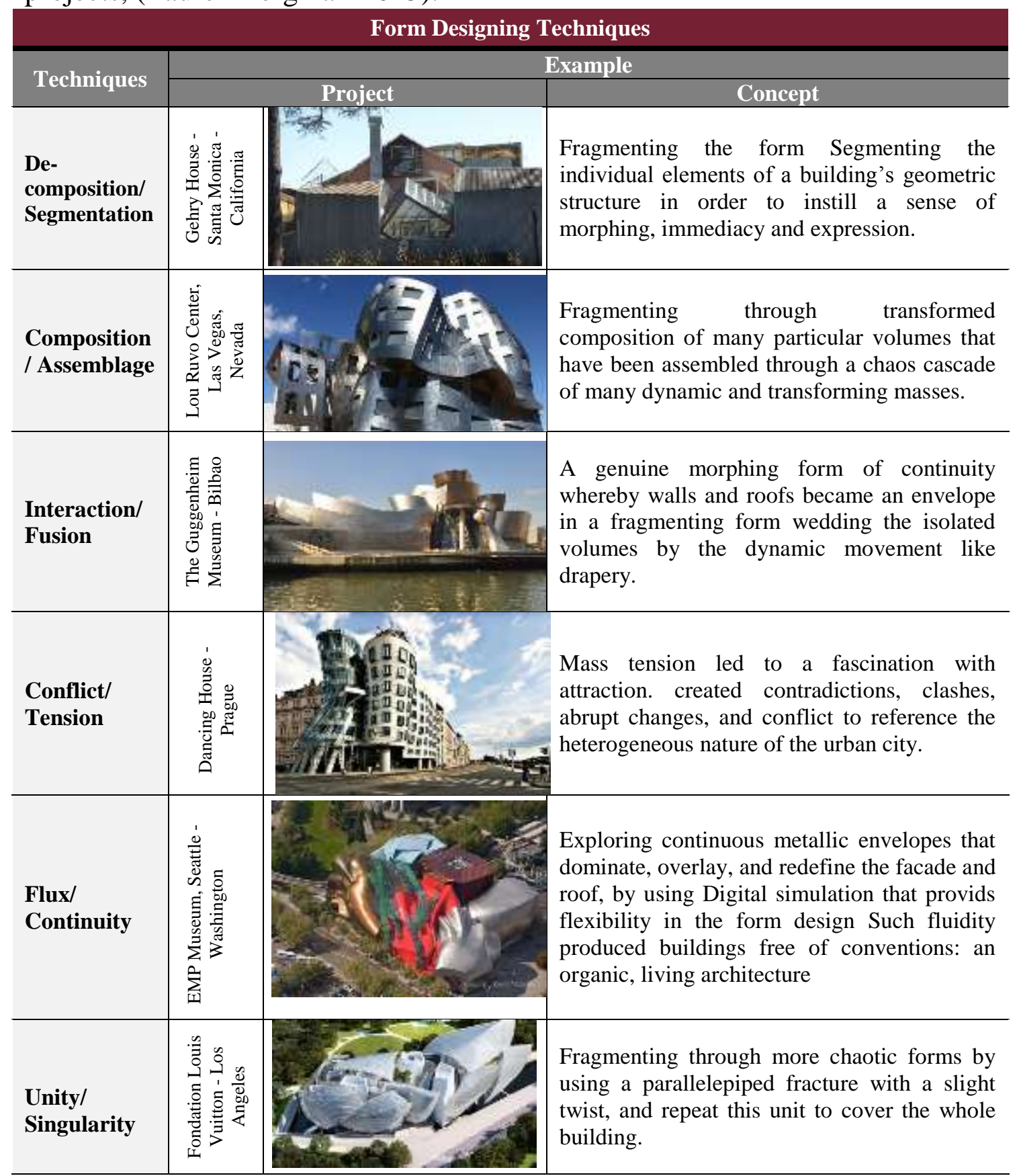




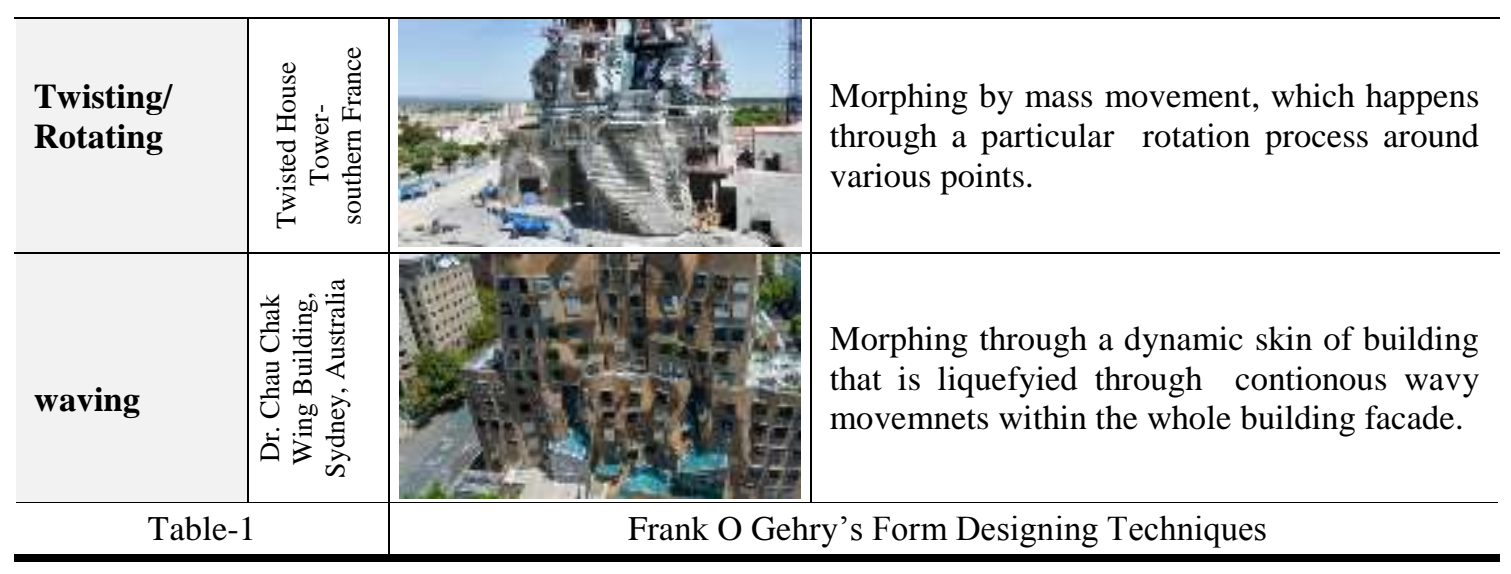

\subsection{Morphing Methodologies in Coop Himmelblau's Thoughts:}

In twentieth century architects' few of them works resist interpretation so strongly as those of Coop Himmelblau. For more than thirty years the Coop Himmelblau partnership of Wolf Prix and Helmut Swiczinsky have avoided popular styles and trends to produce a series of enigmatic and poetic buildings, projects and texts. From their earliest experiments with exploding spaces and kinesthetic clothing to their most recent completed buildings. Their argumentative and frequently hermetic projects have aroused both great public support and condemnation, and their manifestos

have become mantras for the next generation of architects. Yet there is much in their work that has never been explained, and theorists and critics are divided over how to interpret their works. Conventionally Coop Himmelblau is regarded as being complicit in attempts to undermine or subvert the dominant ideologies and methodologies of architecture. Coop Himmelblau expresses the coincidence of order and chaos, and the heterogeneity of urban space, through an iterative design method that incorporates both graphical and philosophical operations. They describe themselves as seeking an architecture which "will mirror the complexity of our intellectual and cultural life, as the expression of our urban culture.", (Coop Himmelblau-1994). They argue that in a world that is , becoming daily more and more fragmented a new model of architecture is required that can respond to the spatial and social needs of the populace. Despite such statements they are strangely reticent about describing just how their architecture achieves these goals, and much that is known about their methods is contradictory, (Coop Himmelblau-1991). So it can be stated that the architecture of Coop
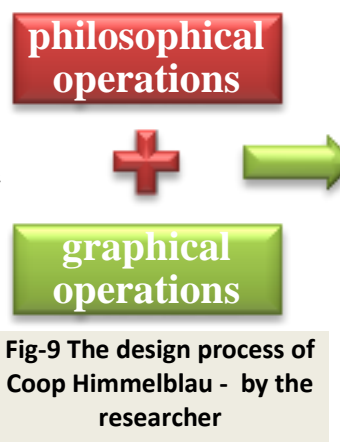
researcher Himmelblau is a physical evocation of concepts derived from chaos theory and fractal geometry, (Michael Sorkin-1991).

The design process of Coop Himmelblau can be described as an integrated operation which started with a deep philosophical research about the project constrains, aspects and goals, then they redefined their goals according to "chaos theory", Consequently, they convert their thoughts through a developed graphical 
operation, which combined cascades of fractal and fragmental geometries that merged together to reach a unique morphing forms that represents the concept of complexity, (Coop Himmelblau-1991), as shown in fig-9.

\section{- Coop Himmelblau 's Techniques in Form Finding:}

Coop Himmelblau developed many design techniques which reflect his thoughts of chaos and to reach the level of complexity that they always seek for. So it can be observed that their techniques depended on fracturing and fragmentation of the form geometries through different ways as will be shown in the following table- 2 .

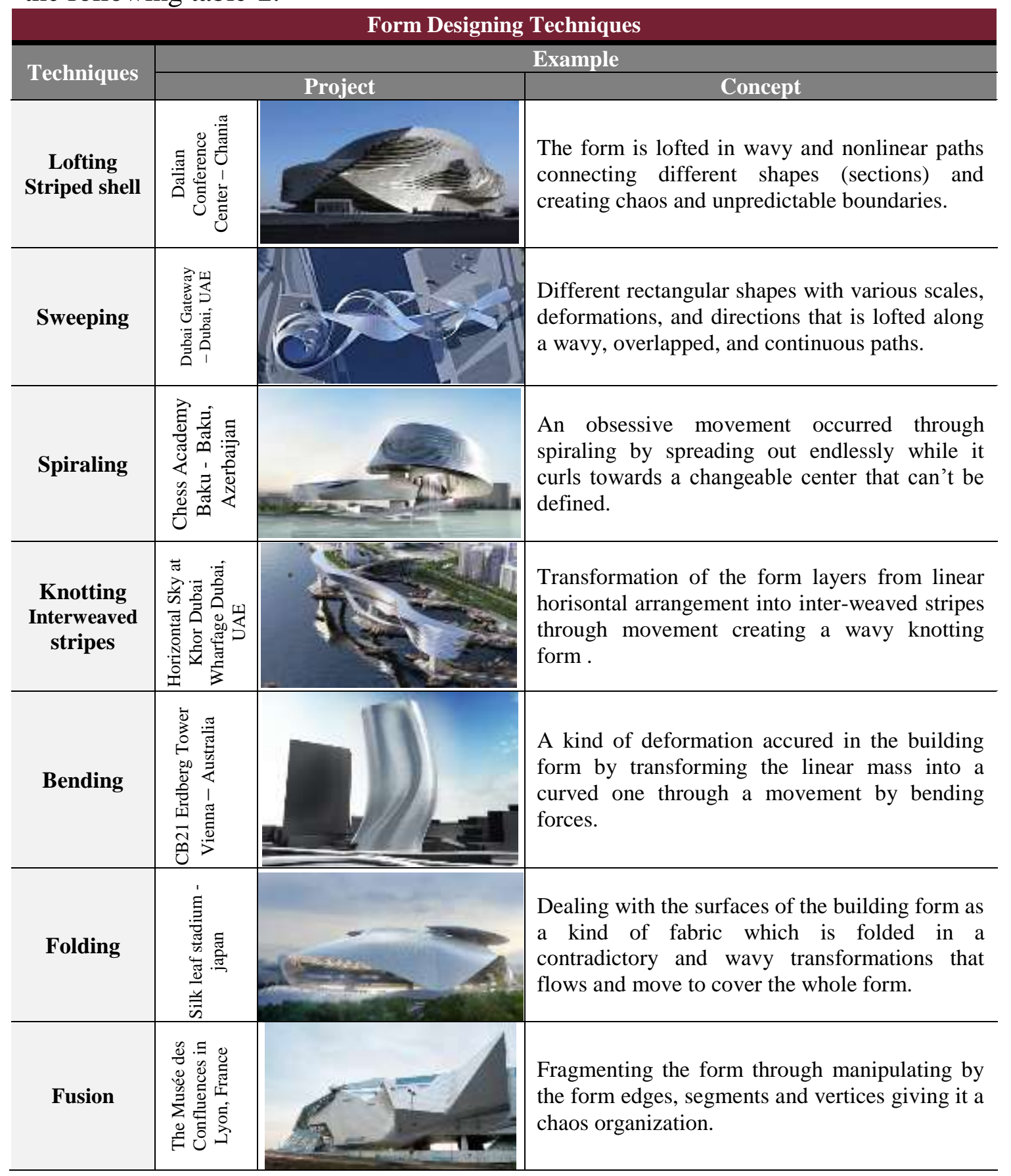




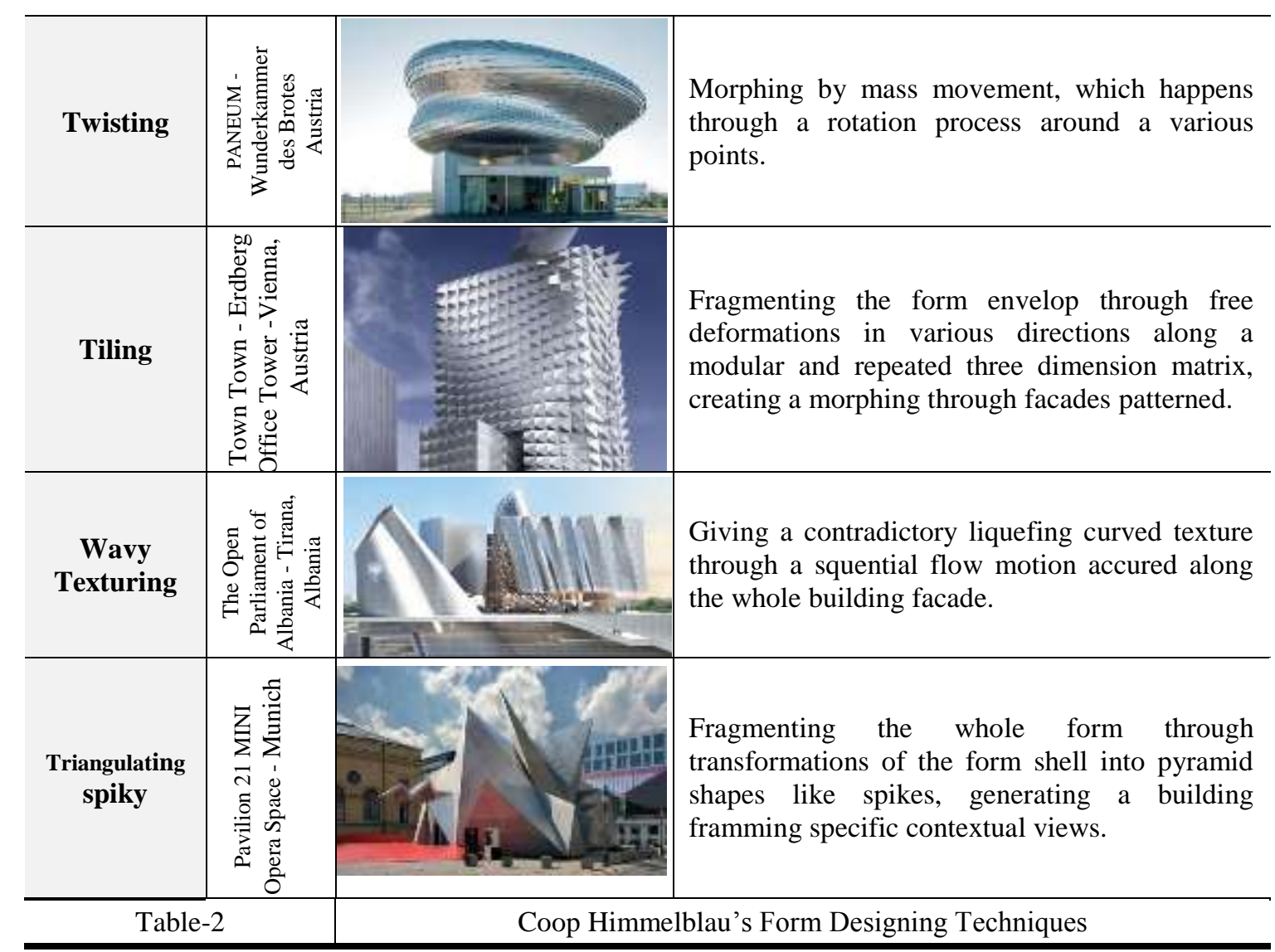

\subsection{Morphing Methodologies in Zaha Hadid's Thoughts:}

Hadid has declared frequently that her early projects are inspired from suprematism, which was a trends of art appeared to be more abstract in expression like impressionism, cubism, futurism, and suprematism, (Dezeen -2012). She was also one of the important pioneers of deconstruction movement which was influenced by the fast development of science and technology, so architects have the desire to give the real picture of their time and reflect it in their buildings, (S. Hattenstone-2012).

Then appeared parametricism trend, it is a new style in architecture and urban design, the early emergence of parametricism could be traced to the mid1990s in the digital animation techniques. This style has been launched by Zaha Hadid architects, namely Patrick Schumacher who is a lecturer at architectural association in London, the main activist in establishing such trend and Zaha's partner architect in many of her designs especially the latest ones, (Y. Futagawa2010).

Parametricism architectural style is based on innovative design research programs which develop gradually and parallel with the advanced progresses occurring in the computational sector. These programs: MEL-Script, parametric modeling, and Rhino give variable and different innovative forms that could be enhanced by the aesthetical sense of the architect or designer. Forms generated by these programs are featured by morphing and dynamic change which grabs our minds to the ones used in science fiction films. These programs have the ability to ingeniously connect the design of the interior spaces with the exterior form and 
even within a large domain such as the form of landscape and urban planning to portrait them as a one system, (N. Leach -2009)

Hadid is famous by pushing boundaries of space, design, architectural convention. She creates her radical rules of design strategy that are resulted from admixture of her experiences of long journey in design and rationalism, because of being a good observer of art, nature, architecture and effective surrounding aspects, she searches for the sources of their aesthetics and factors that attracting people to them and then applies them in her works. This eager of searching helps Hadid to obtain some primary skills diligently developed by her to became her own techniques, (Amatalraof Abdullah-2013).

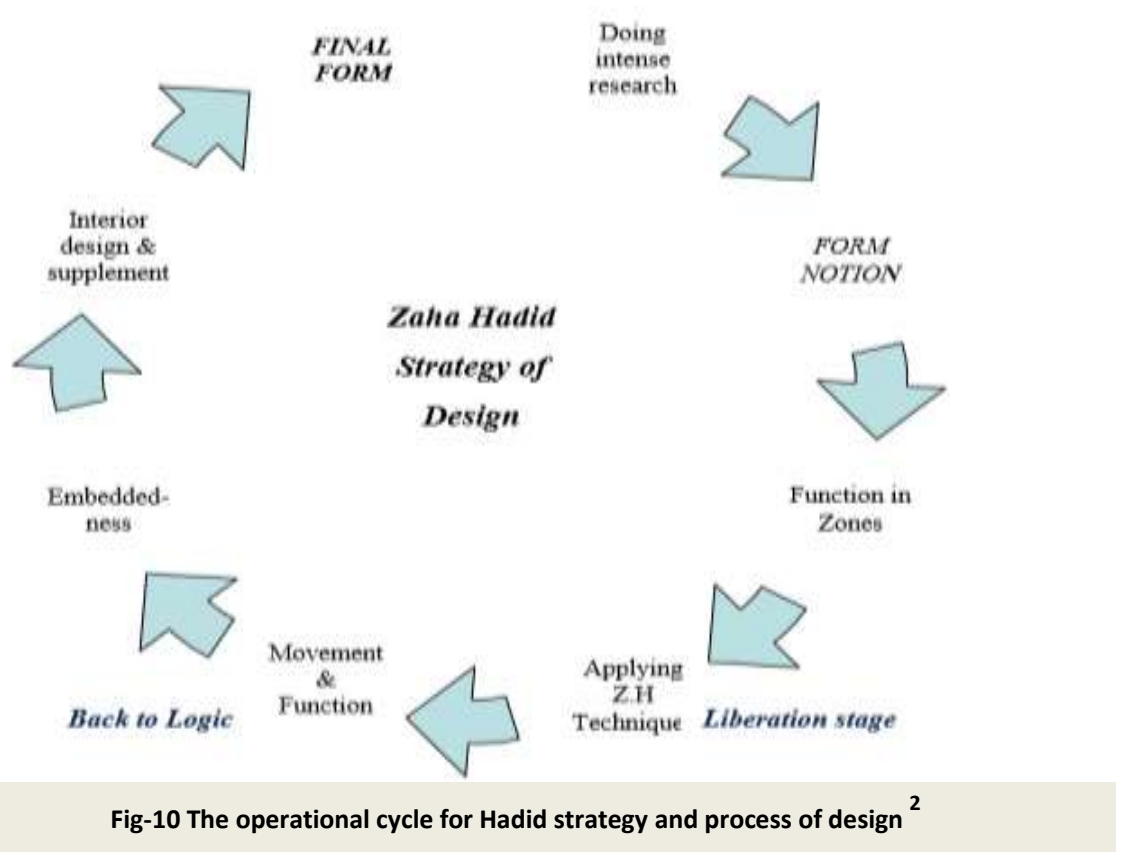

As we see from this fig-10 it can be concluded that hadid developed the traditional design process by applying her own techniques in the phase of form design which considered as the liberation stage, and how she merged it with function and returning it back to logic, reaching finally the final project form.

\section{- Zaha Hadid's Techniques in Form Finding:}

Hadid's self-developed many techniques in designing form through the liberation stage, which depended in many of them on the morphing concept. Each technique has various ways applied in different projects. It is important to remind that using such techniques could result in producing Hadid's architecture-like. Fig15 shows these techniques and the different ways of their application through form design process, in which the techniques are classified into: abstraction and fragmentation, landscaping the project, defying gravity, layering, play of light and seamlessness and fluidity, (Amatalraof Abdullah-2013). 


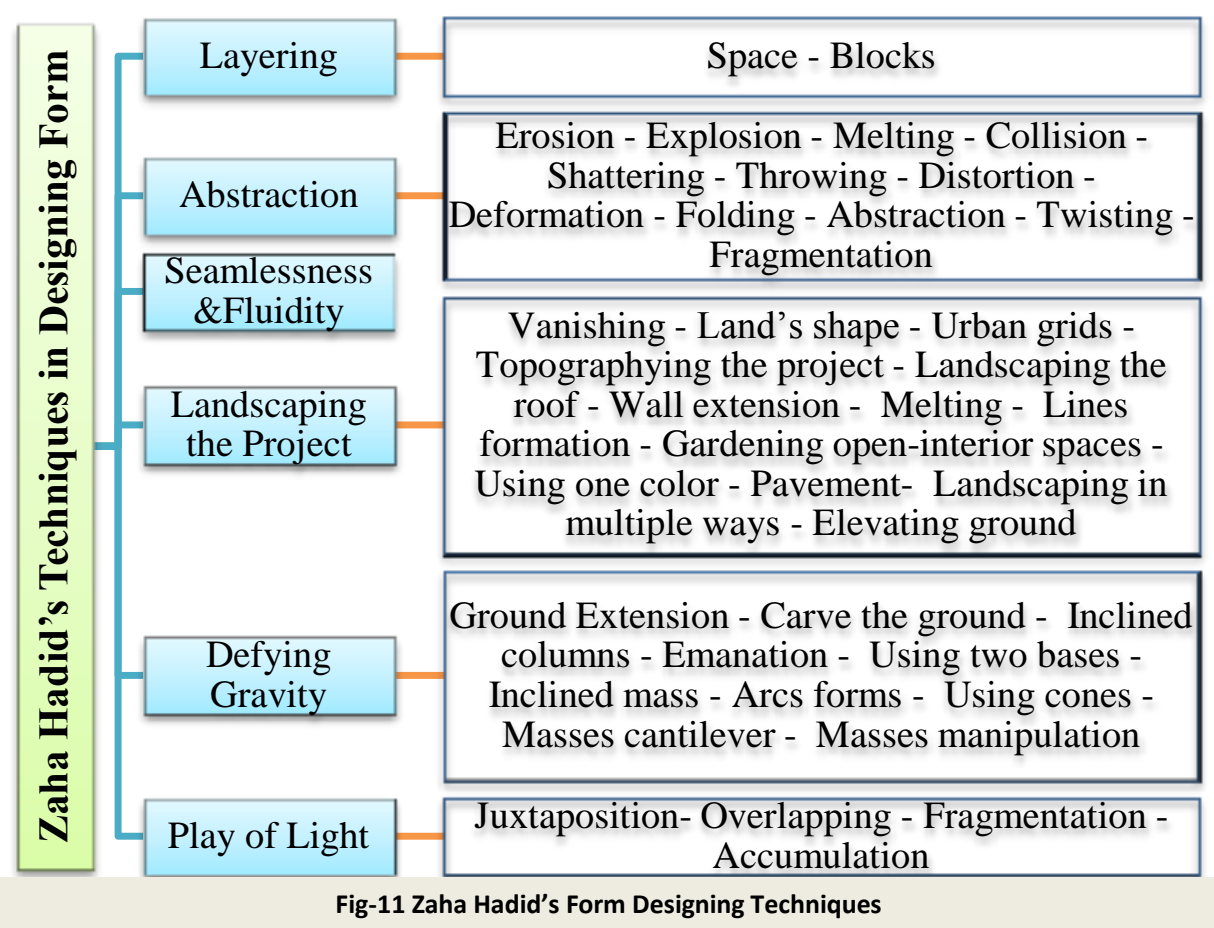

Form the previous fig-11 the research will concentrate on the most important techniques that dealt with the morphing concept, which will be illustrated through the following:

\subsubsection{Abstraction Techniques:}

Through Hadid's hard investigation in designing space, she discovered abstraction and fragmentation as a helpful principle for creating and discovering innovative spaces, in addition to being a technique to unbounded invention. She claimed that these techniques offered her a vision for the trajectory of lines and that her works are generated by having the eagerness to follow a line and imagine it when it morphs, changes and distorts. Consequently, Hadid applied abstraction and fragmentation in various ways to generate form and space; the most exciting one is embodying natural phenomena's occurrence and depicting their act process as a form notion for projects, as shown in following table-3, (J. Michaud-2012)

\begin{tabular}{|c|c|c|c|}
\hline \multicolumn{4}{|c|}{ Abstraction Techniques } \\
\hline \multirow{2}{*}{ Techniques } & \multicolumn{3}{|c|}{ Example } \\
\hline & & Project & concept \\
\hline $\begin{array}{l}\text { Erosion - } \\
\text { Porosity }\end{array}$ & 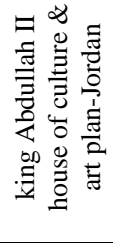 & E. & $\begin{array}{l}\text { Morphing through Fragmenting by gradual } \\
\text { wiping for the building mass, to make the } \\
\text { design porous giving the sense of } \\
\text { continuation between inside and outside }\end{array}$ \\
\hline Folding & 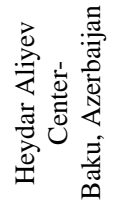 & & $\begin{array}{l}\text { Wavy transformations occurred through } \\
\text { manipulating of the surfaces by folding } \\
\text { movements through various directions like } \\
\text { a piece of fabric or paper. }\end{array}$ \\
\hline
\end{tabular}




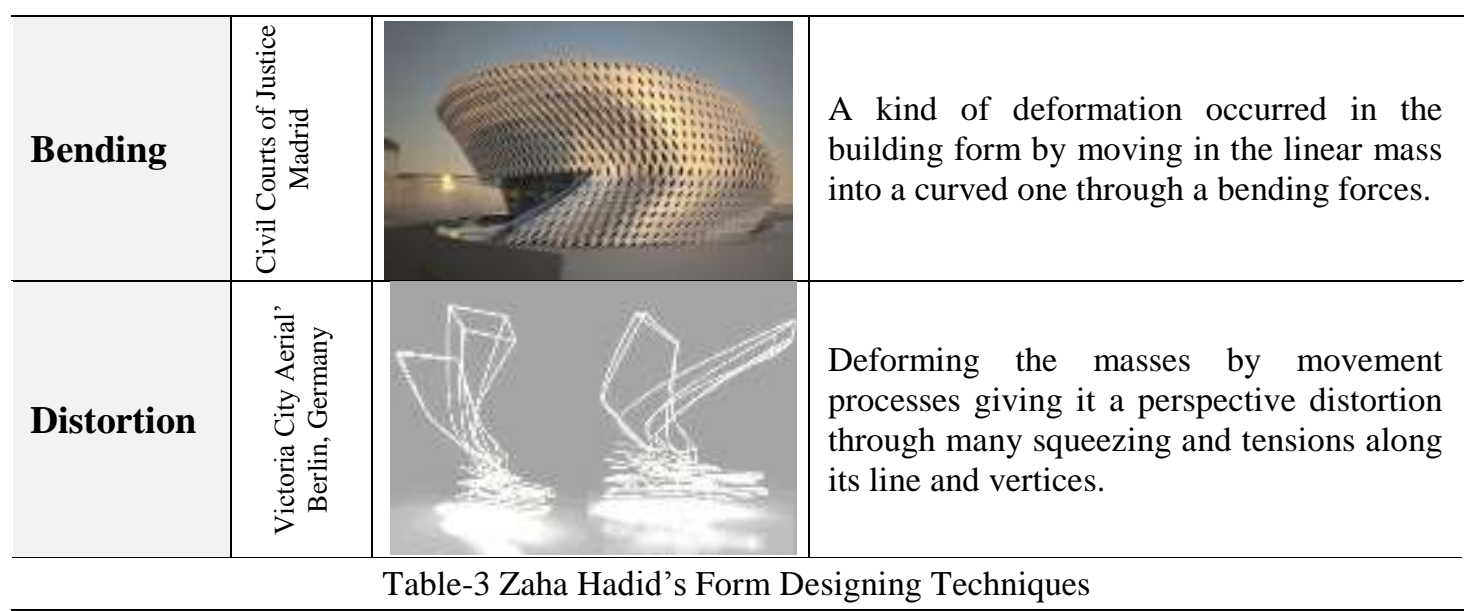

\subsubsection{Landscaping the Project:}

Hadid tries as much as possible to embed and melt the project within the context by considering all the possible articulated relationships such as topography and landscape. Through design process, Hadid tries to derive some features from the context to project and vice versa to guarantee a harmonic combination into each other, Using this method affects both the general form and orientation of the building, making them dissolve and shape a new kind of landscape to be a complementary part of modern cities. Hadid used a lot of techniques to achieve this concept that will be illustrate through the following table-4, (Z. Hadid-2013).

\begin{tabular}{|c|c|c|c|}
\hline \multicolumn{4}{|c|}{ Landscaping the Project Techniques } \\
\hline \multirow{2}{*}{ Techniques } & \multicolumn{3}{|r|}{ Example } \\
\hline & & Project & concept \\
\hline Melting & 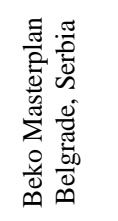 & & $\begin{array}{l}\text { Forming cluster of buildings that gradually } \\
\text { flow and liquefied into one another, to unite the } \\
\text { city and tying the urban fabric together. }\end{array}$ \\
\hline Vanishing & 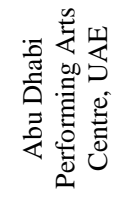 & & $\begin{array}{l}\text { The mass transformed through gradual growing } \\
\text { up or fades away in its scale through } \\
\text { liquefying, creating a strong connection } \\
\text { between them form and site. }\end{array}$ \\
\hline $\begin{array}{l}\text { Scaling } \\
\text { fractals }\end{array}$ & 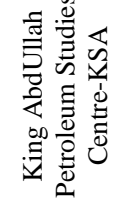 & & $\begin{array}{l}\text { Morphing through fragmenting the form by } \\
\text { using fractal fabric and changing the scale of } \\
\text { fractal unit randomly. }\end{array}$ \\
\hline $\begin{array}{l}\text { Wall } \\
\text { extension } \\
\text { and lines } \\
\text { formation }\end{array}$ & 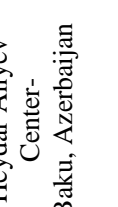 & & $\begin{array}{l}\text { Expanding and folding the walls of the building } \\
\text { to form the pavement of the site designed in a } \\
\text { way that gives a sense of affiliation to the earth. }\end{array}$ \\
\hline Table - & & & 's Form Designing Techniques1 \\
\hline
\end{tabular}




\subsubsection{The Ground and Gravity:}

Hadid is the most well-known architect who used this technique; the technique of breaking free from the ground. The idea of the ground is a critical issue for most of her projects. She shakes the frozen notion of the ground floor by letting parts of it stay up without support through carving masses, floor grid tightens, mass inclining and sometimes she makes it porous in order to let some elements to work individually. that will be illustrate through the following table-5.

\begin{tabular}{|c|c|c|c|}
\hline \multicolumn{4}{|c|}{ Ground and Gravity Techniques } \\
\hline \multirow{2}{*}{ Techniques } & \multicolumn{3}{|r|}{ Example } \\
\hline & \multicolumn{2}{|r|}{ Project } & concept \\
\hline $\begin{array}{l}\text { Carve the } \\
\text { Ground }\end{array}$ & 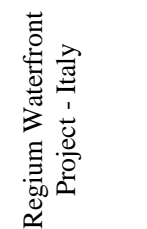 & 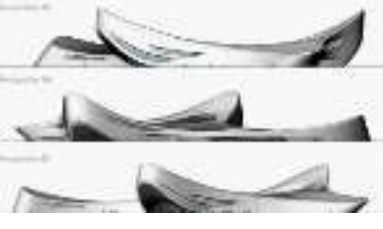 & $\begin{array}{l}\text { Kind of transformation by carving the } \\
\text { ground up through tension force to the sky as } \\
\text { if the building wants to get free from the land } \\
\text { and fly. As a way of energizing the building } \\
\text { façade. }\end{array}$ \\
\hline $\begin{array}{l}\text { Grid } \\
\text { Tighten }\end{array}$ & 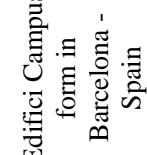 & & $\begin{array}{l}\text { A planer morphing occurred through } \\
\text { tightening and tension the grid of each floor } \\
\text { in various directions and cantilevers scales. }\end{array}$ \\
\hline Table & & Zaha Hac & id's Form Designing Techniques ${ }^{1}$ \\
\hline
\end{tabular}

\section{Conclusions:}

From the previous study to the design processes of most famous contemporary architectural pioneers, it can be concluded that the design process has been changed in a reverse way, whereas form became the main motive and the real start in their design processes, and this was due to the potential of new computing technologies in a wide range of application, that facilitate Morphing through form finding stage. In this context the research will propose a new design process, fig-12, which is extracted from the previous architects' design processes, that is classified into four main processes, which starts with the studies phase then the liberation stage, after that the process return back to the logic stage, and ends with the final
form
stage.

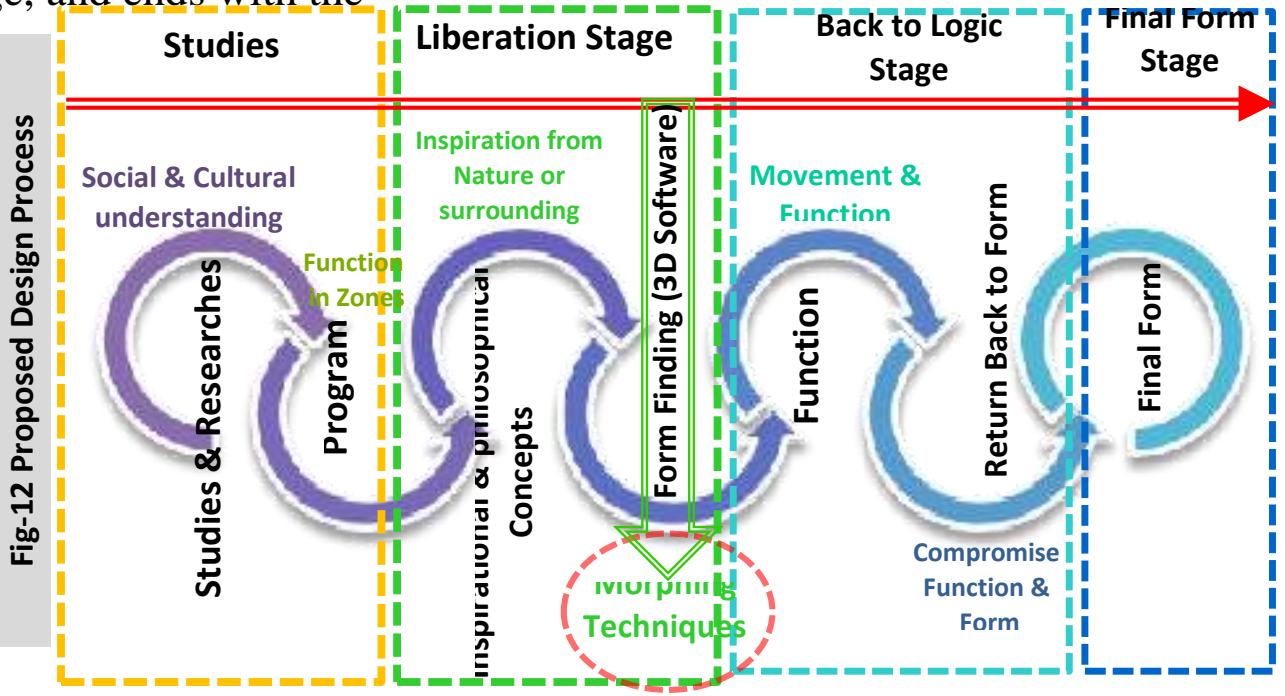




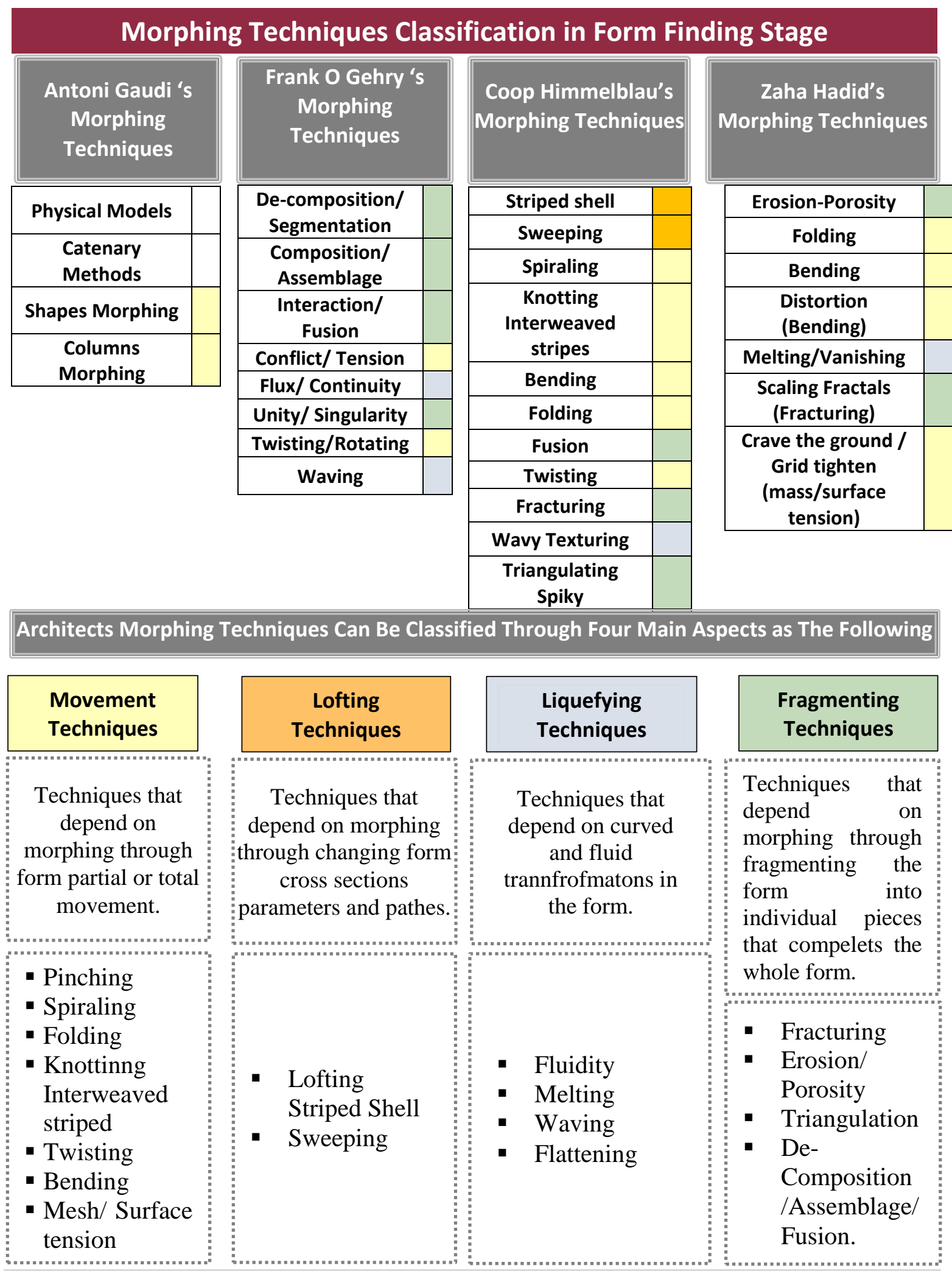

Fig-13 Morphing Techniques Classification in Form Finding Stage of the Architectural Pioneers 


\section{- References:}

1. Amtalraof Abdullah - Zaha Hadid for making strategies for design - Faculty of Built Environment Universiti Teknologi - Malaysia - 2013.

2. Barrois Carlos "Transformations on Parametric Design Models: A Case Study on the Sagrada Familia Columns" - Published Research Massachusetts Institute of Technology - USA - 2005.

3. Burnard Lupen, Christoph Graph "Design and Analysis" - OIO Publisher 1997.

4. Bryan Lawson "How Designers Think: The Design Process Demystified" Elsevier -USA|- 2005.

5. Coop Himmelblau - "Cam pus de Jussieu, Library" - Architecture+ Urbanism No. 283 Is. 4 - Paris, France - 1994.

6. Coop Himmelblau - "On the Edge in Architecture in Transition: Between Deconstruction and New Modernism - ed. Peter Noever Munich: Prestel 1991.

7. Dan Chak "Catenary CAD: An Architectural Design Tool" - Published Research - 2014.

8. Dezeen "Zaha Hadid and Suprematism at Galerie Gmurznska Zurich" Dezeen Magazine - 2012.

9. Dictionary meanings in the Cambridge Dictionary of American English, at Dictionary.com (esp. meanings 1-5 and 7-8) - 2018.

10. Don Kumaragamage, Y. - "Design Manual Vol 1" - 2011.

11. Ela Poursani "Frank Gehry: Design Philosophy \& Process" - published research - Study.com - 2018.

12. H. Simon "The Sciences of the Artificial" - Mass: MIT Press - Cambridge 1969.

13. Jane R. Burry, Mark C. Burry "Gaudi and Cad" - itcon.org - Published research - Australia - 2006

14. J. Michaud - "Zaha Hadid: The Lady GAGA of Architecture" - Published Research - The New Yorker - 2012.

15. Lauren Bergman - "Frank Gehry: An Overview" - Published research 2015.

16. Lian Chang - The Software Behind Frank Gehry's Geometrically Complex Architecture - Published research - priceonomics - 2015.

17. Michael Sorkin - "Exquisite Corpse: Writings on Buildings" - Verso - New York - 1991.

18. N. Leach - "Digital Cities AD: Architectural Design. International house" John Wiley \& Sons - London - 2009. 
19. Santiago Huerta "Structural Design in the Work of Gaudi" - University of Sydney - Architectural Science Review - 2006 - Volume 49.4

20. S. Hattenstone - "Zaha Hadid: 'I'm happy to be on the outside" - Guardian magazine - Retrieve May 10th, 2012.

21. Y. Futagawa - "Zaha Hadid Recent Projects" - A.D.A. EditaTokyo - Tokyo -2010 .

22. Z. Hadid - "Like a breath of fresh air" - Published research - China Daily USA Newspaper - 2013. 